\title{
UTILIZAÇÃO DE JOGOS NO PROCESSO ENSINO-APRENDIZAGEM
}

\author{
MARQUES, Eddie Raoni de Lima ${ }^{1}$ \\ FALCÃO, Glauber Quirino ${ }^{2}$
}

\begin{abstract}
RESUMO: Esse artigo teve como objetivo observar a reação dos discentes a partir da aplicação da ferramenta de jogos como técnica de ensino. Para atender a esse objetivo, foi desenvolvido um estudo de natureza qualitativa, de caráter descritivo, que tomou por orientação a seguinte questão problematizante: qual a reação dos discentes do curso de administração diante da aplicação de jogos no ensino da contabilidade? Os resultados obtidos ratificaram os benefícios referenciados na literatura, apontando que o lúdico permite uma situação educativa cooperativa e interacional, caracterizado pelo prazer em aprender e pelo esforço espontâneo. Os alunos revelaram que a técnica ajudou bastante na assimilação do conteúdo, sendo favorável para o processo de aprendizagem. O instrumento mostrou-se eficaz, contribuindo inclusive para o desenvolvimento do trabalho em equipe.
\end{abstract}

Palavras-chave: Técnica de ensino; Ludicidade; Aprendizagem.

\section{INTRODUÇÃO}

A utilização do lúdico faz com que o aprender se torne mais prazeroso, através da utilização de técnicas de jogos e brincadeiras, a fim de facilitar o conhecimento na aquisição cognitiva do aluno frente às atividades pedagógicas (ROSÁRIO, 2013).

Professores buscam, através de atividades que envolvem o lúdico, dar mais sentido ao assunto que está sendo abordado no intuito de levar o aluno, de forma mais prazerosa, ao aprendizado.

Sem dúvida alguma, o uso do lúdico é, de fato, recurso fundamental de ampliação e representação do conhecimento. A utilização do lúdico nas aulas evidencia-se como uma atividade que rompe com barreiras disciplinares, torna permeável as suas fronteiras e caminha em direção a uma postura interdisciplinar para compreender e transformar a realidade em prol da melhoria da qualidade de vida pessoal, grupal e global (PESSOA, 2012).

\footnotetext{
${ }^{1}$ Mestrando em Controladoria na Universidade Federal Rural de Pernambuco. Endereço Postal: Rua Vidal de Negreiros, 153, Nossa Senhora das Dores, CEP 55.004-430, Caruaru-PE. Endereço Eletrônico: eddieraoni@hotmail.com.

${ }^{2}$ Mestrando em Controladoria na Universidade Federal Rural de Pernambuco. Endereço Postal: Rua Marechal Deodoro, 503, apto 1504, Encruzilhada, CEP 52.030-172, Recife-PE. Endereço Eletrônico: glauber.falcao@gmail.com.
}

Criar Educação, Criciúma, v. 6, №1, janeiro/junho 2017.- PPGE - UNESC 
Ao optar pelo jogo como estratégia de ensino, o professor o faz com uma intenção: propiciar a aprendizagem, tendo como propósito o ensino de um conteúdo ou de uma habilidade. Dessa forma, o jogo escolhido deverá permitir o cumprimento deste objetivo (MOURA, 1992).

O objetivo geral do estudo é observar a reação dos discentes a partir da aplicação da ferramenta de jogos como técnica de ensino na disciplina Introdução a Contabilidade, no curso de Administração.

A utilização de jogos pode facilitar o processo de aprendizagem de várias disciplinasde inúmeros cursos além de fazer com que os alunos possam trabalhar em equipe.Aquestão problematizante desse estudo é: qual a reação dos discentes do curso de administração diante da aplicação de jogos no ensino da contabilidade?

Estudos abordam preocupação com a aprendizagem. Sobre esse assunto, Teodoro, Berwig, Cunha, Colauto (2011) apontam que o ambiente acadêmico tem se preocupado com o desenvolvimento de novas metodologias e atitudes para melhorar a efetividade no processo de aprendizagem. Nesse sentido, a proposta desse estudo, se justifica pela importância de contribuir com reflexões acercade melhores técnicas de ensino para uma melhor formação do indivíduo, como também pela grande responsabilidade que tem o educador para alcançar a aprendizagem dos educandos fazendo-se a integração dos conteúdos curriculares propostos com 0 lúdico.Todos têm o direito de aprender, e aprendendo com prazer o resultado pode ser ainda maior.

O trabalho versou sobre o que é lúdico, sua aplicação no processo de aprendizagem, seus resultados e o que tais práticas concebem na formação dos alunos em seu processo de aquisição cognitiva.

O estudo está organizado em cinco seções, iniciando com essa introdução que apresenta o objetivo e a justificativa do estudo. Posteriormente apresenta-se o embasamento teórico utilizado na sustentação do estudo, contendo dois pontos básicos: O lúdico no ensino da contabilidade e $\mathrm{O}$ processo de aprendizagem. Em seguida é apresentada a metodologia do trabalho, utilizada para desenvolver a pesquisa. Na sequência faz-se a apresentação e discussão de resultados baseados na experiência vivenciada em sala de aula. Ao final, apresentam-se as considerações finais do estudo realizado.

Criar Educação, Criciúma, v. 6, no1, janeiro/junho 2017.- PPGE - UNESC 


\section{EMBASAMENTO TEÓRICO}

Neste tópico são abordadas as bases teóricas para elaboração do relato de experiência, por onde se pretende esclarecer sobre a utilização dolúdico no ensino da contabilidade e o processo de aprendizagem.

\subsection{Lúdico no Ensino da Contabilidade}

Várias são as técnicas de ensino utilizadas pelos professores, Andrade (2002, p. 48-63) apresenta os seguintes métodos e técnicas: aula expositiva, dinâmica de grupo, visitas a empresas, jogos de empresas, dissertações ou resumos, seminário, mesa redonda, resolução de exercícios e estudos de caso.

Não há, portanto, um método ou uma técnica melhor que a outra. A definição da metodologia mais apropriada se dará no momento em que o professor traçar seus objetivos de ensino atrelado ao conteúdo a ser apresentado e ao perfil de cada aluno. Não existem "fórmulas mágicas" quando se trata de aprendizagem. O que deve sempre ocorrer é a preocupação em o que ensinar e de que forma ensinar (ALMEIDA, KUHL, LEITE, PADOAN, 2007).

O professor precisa conhecer seu aluno e entender qual o método de ensino que deve ser adotado com o objetivo de levar o aprendente a compreender o que está sendo abordado em sala de aula.

Uma das técnicas que podem ser utilizadas é o lúdico que, segundo Friedman (1996) proporciona uma situação educativa cooperativa e interacional, ou seja, quando alguém está jogando (brincando) está cumprindo com as regras do jogo e ao mesmo tempo, desenvolvendo ações de cooperação e interação que acaba por estimular a convivência em grupo.

De acordo com Pedroza (2005), o termo "lúdico" está relacionado a "jogo" e "brincar", e o lúdico é algo que permeia, há muito tempo, tanto o universo infantil como também o adulto.

O lúdico apresenta dois elementos que o caracterizam: o prazer e o esforço, Criar Educação, Criciúma, v. 6, ㄲo1, janeiro/junho 2017.- PPGE - UNESC 
ambos de forma espontânea. Ele é considerado prazeroso, por conta da sua capacidade de absorver o indivíduo de forma intensa e em sua totalidade, criando um clima de entusiasmo. É este aspecto de envolvimento emocional que o torna uma atividade com forte potencial motivacional (NOGUEIRA).

Através do lúdico, o aluno pode aprender se divertindo, ou seja, fazendo relação dos conteúdos programáticos com os jogos e as brincadeiras, deixando para trás o método tradicional de ensino, que na maioria das vezes é composto apenas de aula expositiva, e aprendendo os conteúdos das disciplinas numa forma mais prazerosa e divertida.

O lúdico é subjetivo, dessa forma, permite fazer relação com o processo de ensino aprendizagem. Pois, o prazer pelas brincadeiras está presente em todos (OLIVEIRA, 2010).

Os jogos lúdicos oferecem condições de o aprendente vivenciar situaçõesproblemas, a partir do desenvolvimento de jogos planejados e livres que permitam uma vivência no tocante às experiências com a lógica e o raciocínio permitindo, inclusive, atividades físicas e mentais que favorecem a sociabilidade e estimulam as reações afetivas, cognitivas, sociais, morais, culturais e linguísticas (SANTOS e JESUS, 2010).

O uso da ludicidade, hoje, direcionada tanto para crianças, jovens ou adultos em diferentes ambientes como escolas, empresas, universidades, hospitais, tem que ser tratada com cientificidade para poder ser um fator transformador (SANTOS, 2001).

\subsection{Processo de Aprendizagem}

Investigações abordam fatores que interferem no processo de aprendizagem. Para Mazzioni (2013), vários são os fatores que interferem nos resultados esperados: as condições estruturais de uma instituição de ensino, as condições de trabalho dos professores envolvidos no processo de ensino, as condições sociais dos aprendentes, os recursos que se encontram disponíveis. Outro fator é o de que as estratégias de ensino utilizadas pelos docentes devem ser capazes de motivar e de envolver os alunos ao aprendizado (MAZZIONI, 2013).

Criar Educação, Criciúma, v. 6, no1, janeiro/junho 2017.- PPGE - UNESC 
Priorizando sempre pela aprendizagem dos alunos, o professor deve observar alguns aspectos que interferem para que bons resultados sejam alcançados em relação ao crescimento e desenvolvimento cognitivo, físico e motor dos aprendentes. Para que a estratégia de ensino tenha sucesso, o professor deve ficar atento aos seus alunos para que a escolha de uma prática condizente seja efetivada (RODRIGUES, 2015).

Não basta que os alunos em sala de aula só recebam informação e façam alguns exercícios de fixação sobre o conteúdo para que os mesmos possam vir a aprender. Eles devem ter um papel mais ativo em sala, passando a ser o centro do processo de ensino/aprendizagem (MOSER, 2004).

Os alunos devem ter a oportunidade de internalizar as informações dadas de maneira que sejam significativas, por isso a importância de atividades que deem a oportunidadeda assimilação do conteúdo dado, e a sala de aula deve ser um espaço para isso (AUSUBEL,1978).

Acreditamos, assim como Kishimoto(1996), que o professor deve observar a utilização de propostas pedagógicas passando a adotar em seu trabalho aquelas que atuem nos componentes internos da aprendizagem, já que estes não podem ser deixados de lado quando o objetivo é a apropriação de conhecimentos por parte do aluno.

O professor deve auxiliar na tarefa de formulação e de reformulação de conceitos impulsionando o conhecimento prévio dos alunos com uma introdução da matéria que associe esses conhecimentos à nova informação que está sendo apresentada (POZO, 1998), e utilizando meios didáticos para facilitar a compreensão do conteúdo pelo aluno.

Peleias (2006, p. 133) atribui ao professor a tarefa de auxiliar o aluno no processo ensino-aprendizagem, e à instituição de Ensino Superior, a responsabilidade de preparar os docentes para esse fim. O mesmo autor define aprendizagem como sendo o processo de desenvolvimento do conhecimento, de como se aprende e define processo de ensino como o conjunto de ações adotadas para se promover a aprendizagem. Um não existe sem o outro; a aprendizagem é o fim, o ensino é o meio. A conjunção desses fatores recebe o nome de processo ensino-aprendizagem.

Criar Educação, Criciúma, v. 6, no1, janeiro/junho 2017.- PPGE - UNESC 
Vários são os fatores que envolvem o processo de ensino-aprendizagem, no entanto os que mais se destacam são: o professor e a forma com que atua na sala de aula e, o aluno e a maneira com que aprende (ALMEIDA, KUHL, LEITE, PADOAN, 2007).

O jogo pedagógico ou didático é aquele criado com o intuito de proporcionar determinadas aprendizagens, diferenciando-se do material pedagógico, por conter o aspecto lúdico Cunha (1988), e utilizado para atingir determinados objetivos pedagógicos, sendo uma alternativa para se melhorar 0 desempenho dos estudantes em alguns conteúdos de difícil aprendizagem (Gomes et al, 2001).

Neste sentido, o jogo ganha um espaço como a ferramenta ideal da aprendizagem, na medida em que propõe estímulo ao interesse do aluno, desenvolve níveis diferentes de experiência, tanto pessoal como social, ajuda a construir suas novas descobertas, desenvolve e enriquece sua personalidade, e simboliza um instrumento pedagógico que leva o professor à condição de condutor, estimulador e avaliador da aprendizagem (CAMPOS, BORTOLOTO, FELÍCIO, 2003).

\section{METODOLOGIA DO TRABALHO}

A análise e descrição da metodologia desenvolvida nesse trabalho foram divididas em três grupos: caracterização da pesquisa; elaboração do jogo; e realização da dinâmica.

\subsection{Caracterização da pesquisa}

O procedimento técnico utilizado nesse estudo é um Levantamento (survey), que de acordo com Prodanov e Freitas (2013, p.57): "esse tipo de pesquisa ocorre quando envolve a interrogação direta das pessoas cujo comportamento desejamos conhecer através de algum tipo de questionário".

Com relação ao objetivo da pesquisa, considera-se como descritivo, pois de acordo comGil (2002, p.42): 
As pesquisas descritivas têm como objetivo primordial a descrição das características de determinada população ou fenômeno ou, então, o estabelecimento de relações entre variáveis. São inúmeros os estudos que podem ser classificados sob este título e uma de suas características mais significativas está na utilização de técnicas padronizadas de coleta de dados, tais como o questionário e a observação sistemática.

A pesquisa é classificada como qualitativa quanto à abordagem do problema, seguindo o que é exposto porSilva e Menezes (2001, p.20):

\begin{abstract}
Pesquisa Qualitativa: considera que há uma relação dinâmica entre o mundo real e o sujeito, isto é, um vínculo indissociável entre o mundo objetivo e a subjetividade do sujeito que não pode ser traduzido em números. A interpretação dos fenômenos e a atribuição de significados são básicas no processo de pesquisa qualitativa. Não requer o uso de métodos e técnicas estatísticas. O ambiente natural é a fonte direta para coleta de dados e o pesquisador é o instrumento-chave. É descritiva.
\end{abstract}

O universo observado foram estudantes de graduação, do Curso de Administração da Universidade Federal Rural de Pernambuco - UFRPE, que cursavam a disciplina Introdução a Contabilidade. Ao todo foram seis alunos participantes da dinâmica e foi utilizado um questionário como instrumento de coleta de dados, que permitiu registrar a reação dos discentes diante da aplicação da dinâmica.

\title{
3.2Elaboração do jogo
}

Como um dos objetivos era facilitar o processo de aprendizagem da disciplina contábil, o jogo foi pautado no conteúdo programático da cadeira ofertada de Introdução a Contabilidade. Assim, a construção do material do jogo envolveu três grupos de assuntos distintos, que são: conceitos e princípios contábeis; livros contábeis; e contas patrimoniais.

Cada grupo de assunto abordado envolveu um tipo de atividade distinta, conforme a seguinte descrição:conceitos e princípios contábeis, aqui a atividade proposta era completar as lacunas de 14 frases com termos contábeis previamente expostos de forma dispersa; livros contábeis, nesse grupo existiam 07 sentenças envolvendo o assunto, com espaços para o aluno marcar verdadeiro ou falso; e contas patrimoniais, onde foram selecionadas 10 contas patrimoniais, para o aluno assinalar qual grupo e subgrupo do balanço patrimonial tais contas pertencem. 
Ressalta-se que o modelo das perguntas aplicadas nas atividades desenvolvidas foi baseado nos jogos do site "Só Contabilidade", acessado em 26/05/2016 e disponível em: <http://www.socontabilidade.com.br/jogos.php >.

\subsection{Realização da dinâmica}

A dinâmica foi dividida em três fases, destacadas a seguir.

\subsubsection{Apresentação}

Esse foi o momento da apresentação dos pesquisadores, como também de toda orientação pedagógica da prática adotada. Dentre as orientações realizadas destacam-se:contextualização da interdisciplinaridade entre a Administração e Contabilidade;explanação das regras do jogo; e divisão das equipes, que foram formadas por dois grupos com três alunos cada.

Ressalta-se que, apesar de existir esse momento inicial de apresentaçãoe orientação pedagógica da atividade, os estudiosos evidenciaram para os discentes que a qualquer momento poderia ocorrer esclarecimento de dúvidas. Ou seja, foi estabelecidoum livre canal de comunicação entre discentes e docentes, favorecendo também o ambiente de aprendizagem.

\subsubsection{Realização do jogo}

O jogo foi dividido por grupo de assunto, ou seja, primeiro os alunos tiveram 05 minutos para responder a atividade envolvendo os conceitos e princípios contábeis. Posteriormente eles tiveram mais 05 minutos para a dinâmica em torno dos livros contábeis e por fim, mais 05 minutos para a atividade com as contas patrimoniais. Vale ressaltar que entre uma atividade e outra eram realizadas as correções e discussões dos materiais respondidos pelas equipes, onde cada acerto garantia um ponto para a equipe. Destaca-se também, que a equipe que terminasse a execução do grupo de atividade primeiro, ou seja, dentro do tempo previsto de 05 minutos por assunto abordado, ganhava 02 pontos extras. Ao término do ciclo de Criar Educação, Criciúma, v. 6, nº1, janeiro/junho 2017.- PPGE - UNESC 
CRIAR EDUCAÇÃO

Revista do Programa de Pós-Graduação em Educação - UNESC

execução do jogo, foram somados os pontos de cada equipe e a vencedora ganhou uma premiação simbólica.

\subsubsection{Abordagem dos alunos}

Após a conclusão da dinâmica, os alunos receberamum questionário, como instrumento de coleta de dados, contendo quatro questões fechadas e um espaço com comentários, críticas e sugestões, para poder subsidiar os resultados da pesquisa envolvendo as práticas executadas.

Destaca-se que as questões fechadas possuíam três tipos de resposta: sim, não e não sei.

\section{APRESENTAÇÃO E DISCUSSÃO DE RESULTADOS}

O instrumento de coleta de dados foi respondido por todos os seis alunos e com isso, permitiu-se traçar a reação dos discentes em relação ao uso de jogos como técnica de ensino.

Para melhor visualizar os resultados, a seguir serão expostos os cinco grupos de resposta obtidos através do questionário.

\subsection{Objetivos}

A primeira questão abordada envolveu a seguinte pergunta: os objetivos foram percebidos de forma clara?

Os pesquisadores consideraram esse o ponto inicial da observação da reação dos discentes, pois o entendimento claro e preciso dos objetivos da dinâmica é fundamental para o desenvolvimento das atividades. Assim, foi dedicado um momento específico para apresentação dos objetivos e regras das atividades a serem desempenhadas em sala.

Como resultado, todos os alunos consideraram que os objetivos foram Criar Educação, Criciúma, v. 6, nº1, janeiro/junho 2017.- PPGE - UNESC 
percebidos de forma clara.

\subsection{Processo de aprendizagem}

Como segundo ponto avaliado, promoveu-se a pergunta: a dinâmica utilizada favoreceu o processo de aprendizagem da disciplina?

Nessa questão, todos os alunos afirmaram que a dinâmica favoreceu no processo de aprendizagem. Ressalta-se que as atividades trabalhadas no jogo eram de temas já abordados em sala de aula, ou seja, os assuntos envolvidos já tinham sido previamente ministrados de forma teórica.

Um ponto a se destacar na dinâmica aplicada foram os momentos de correção das atividades, onde era aberto o espaço para o diálogo com os alunos, permitindo que os mesmos tirassem dúvidas, assim ocorria a troca de experiências em torno da temática.

Com isso, percebe-se que o uso da ferramenta de jogos, aliado aos momentos de interação com os alunos, facilita o processo de consolidação dos assuntos ministrados e consequentemente colabora no processo de aprendizagem.

\subsection{Regularidade do uso da técnica}

A terceira questão realizada foi construída de seguinte forma: você gostaria que o uso de jogos, no processo de aprendizagem, fosse adotado de forma regular nas disciplinas do seu curso?

Esse questionamento apresentou dois tipos de respostas diferentes, onde cinco alunos afirmaram que gostariam que este tipo de técnica fosse adotada de forma regular entre as disciplinas. No entanto, um aluno marcou não saber responder essa pergunta.

A pergunta proposta teve a intenção de avaliar o interesse na regularidade da prática proposta. Nisso, apesar de um discente não saber opinar, verificou-se que a grande maioria dos alunos tem interesse na prática regular de jogos como uma ferramenta de aprendizagem. 


\subsection{Trabalho em equipe}

Com relação ao quarto questionamento, perguntou-se que: esse tipo de dinâmica fortaleceu o processo de trabalho em equipe?

Nesse ponto todos os alunos responderam que a dinâmica fortaleceu o processo de trabalho em equipe.

O desenho como a dinâmica foi idealizada (com formação de equipes, tempo para resposta das atividades, premiação simbólica) favoreceu um pequeno cenário de simulação de ambientes de trabalho, que na prática existem convivências em grupo, prazos e metas para serem atingidas.

Assim, práticas regulares desse tipo de dinâmica podem desenvolver habilidades necessárias ao ambiente de trabalho.

\subsection{Opiniões}

O quinto levantamento realizado no questionário foi um espaço em aberto para os alunos discorrerem sobre comentários, críticas e sugestões. Sendo assim, serão apresentadas abaixo as seis opiniões escritas pelos discentes, como forma de externalizar as reações percebidas.

\begin{tabular}{|l|l|}
\hline Aluno & Opinião \\
\hline 01 & $\begin{array}{l}\text { "A dinâmica foi favorável para a aprendizagem. Seria bom trazer } \\
\text { algum exemplo visual das contas, relatórios ou diários que sejam } \\
\text { mencionados no exercício". }\end{array}$ \\
\hline 02 & "Gostei muito da dinâmica". \\
\hline 03 & $\begin{array}{l}\text { "O método utilizado fortalece o assunto e a fixação trabalhado na } \\
\text { disciplina de maneira criativa e didática. Para quem tem raciocínio } \\
\text { lento seria bom um tempinho a mais para as respostas". }\end{array}$ \\
\hline 04 & $\begin{array}{l}\text { "A dinâmica foi excelente, ajudou bastante na assimilação do } \\
\text { conteúdo, além de fortalecer o espírito de equipe". }\end{array}$ \\
\hline 05 & "Adorei a dinâmica dos jogos, para mim, particularmente, foi ótimo!!! \\
\hline
\end{tabular}

Criar Educação, Criciúma, v. 6, no1, janeiro/junho 2017.- PPGE - UNESC 


\begin{tabular}{|l|l|}
\hline 06 & Facilita muito o aprendizado". \\
\hline 06 & $\begin{array}{l}\text { "Seria interessante que esses processos fossem utilizados até nas } \\
\text { aulas normais, talvez até como forma de avaliação". }\end{array}$ \\
\hline
\end{tabular}

Percebe-se que os conteúdos das opiniões refletem uma avaliação positiva da prática. Os comentários evidenciam queos alunos consideraram o uso da técnica favorável ao aprendizado, inclusive no processo de assimilação dos conteúdos expostos em sala. Outro ponto de destaque são algumas sugestões fornecidas para a melhoria da dinâmica, isso reflete $o$ interesse e comprometimento dos discentes com a atividade desenvolvida em sala.

Por isso, com relação à prática efetuada, ao analisar todos os cinco pontos discutidos na descrição dos resultados, podem-se destacar as seguintes reações percebidas dos alunos: os discentes perceberam de forma clara os objetivos propostos; a dinâmica realizada dos jogos favoreceu o processo de aprendizagem; há um interesse na prática regular desse tipo de atividade; o jogo desenvolvido no ambiente acadêmico estimulou o trabalho em equipe; e por fim as opiniões externalizaram a aprovação do uso da dinâmica.

\section{CONSIDERAÇÕES FINAIS}

Ao se analisar as repostase as opiniões fornecidas pelos discentes através dos questionários aplicados, permitiu-se observar a reação dos mesmos em relação à aplicação de jogos como técnica de ensino, objetivo deste estudo.

As reações verificadas indicam que o uso de jogos facilita o processo de aprendizagem em disciplinas de contabilidade. Porém, é importante ressaltar que a técnica utilizada não substitui as aulas teóricas, mas demonstrou-se que tal ferramenta auxilia no processo de aprendizagem.

Outro ponto analisado das reações foi o estímulo que a dinâmica

Criar Educação, Criciúma, v. 6, ㄲo1, janeiro/junho 2017.- PPGE - UNESC 
desenvolvida contribui para o trabalho em equipe. Prática que deve ser estimulada como forma de preparação para o mercado de trabalho.

Destaca-se que para atingir bons resultados com uso da ferramenta é fundamental a transparência das regras e objetivos, pois favorece a realização da dinâmica e contribui com o comprometimento do aluno.

Sendo assim, diante de todas as reaçõesavaliadas, pode-se concluir queo uso de jogos em disciplinas de contabilidade favorece o processo de aprendizagem, como também desenvolve um cenário de incentivo ao trabalho em equipe, além de criar um ambiente interativo entre discentes e docentes.

Para os docentes que adotarem também uso dos jogos como uma das ferramentas de ensino, indica-se a aplicação da técnica após a explanação teórica do conteúdo, pois irá favorecer o processo de consolidação dos assuntos abordados em aula.

Como sugestão para futuras pesquisas, pode-se desenvolver estudos na mesma área, com uma amostra maior, para comparar os resultados obtidos. Também podem ser realizadas experiências semelhantes, em outras áreas do conhecimento, e com jogos diferentes, para observar a reação de alunos com o perfil de estudo distinto do que foi descrito nesse relato.

\section{REFERÊNCIAS}

ALMEIDA, L. B.; KUHL, M. R.; LEITE, R. M.; PADOAN, F. A. C. Métodos e técnicas utilizadas no ensino da disciplina de contabilidade de custos em cursos de ciências contábeis: um estudo exploratório em instituições públicas de ensino superior no estado do Paraná. Anais do XIV Congresso Brasileiro de Custos. João Pessoa. 2007.

ANDRADE, C. S. de. O Ensino de Contabilidade Introdutória nas Universidades Públicas do Brasil. Dissertação (Mestrado). Faculdade de Economia, Administração e Contabilidade. Universidade de São Paulo. São Paulo, 2002.

AUSUBEL, D.P., NOVAK, J.D. \& HANESIAN, H. Psicologia Educacional. 2.ed. Rio de Janeiro: Interamericana, 1978.

CAMPOS, L. M. L., BORTOLOTO, T. M., \&FELÍCIO, A. K. C. A produção de jogos didáticos para o ensino de ciências e biologia: uma proposta para favorecer a aprendizagem. Caderno dos núcleos de Ensino, 3548, 2003. 
CUNHA, N. Brinquedo, desafio e descoberta. Rio de Janeiro: FAE. 1988.

FRIEDMANN, A. Brincar, crescer e aprender: o resgate do jogo infantil. São Paulo: Moderna, 1996.

GIL, A. C. Como elaborar projetos de pesquisa. 4 ed. São Paulo: Atlas, 2002.

GOMES, R. R.; FRIEDRICH, M. A Contribuição dos jogos didáticos na aprendizagem de conteúdos de Ciências e Biologia. In: EREBIO,1, Rio de Janeiro, 2001, Anais..., Rio de Janeiro, 2001, p.389-92.

KISHIMOTO, T. M. Jogo, brinquedo, brincadeira e a educação. Cortez, São Paulo, 1996.

MAZZIONI, S. As estratégias utilizadas no processo de ensino-aprendizagem: concepções de alunos e professores de ciências contábeis. Revista Eletrônica de Administração e Turismo. V. 2, n. 1, p. 93-109, Jan./Jun. 2013.

MOSER, S. M. C. S. Atividades Lúdicas e Jogos em sala de aula de Língua Estrangeira. Maringá, 2004. Mimeografado.

MOURA, M. O. O jogo e a construção do conhecimento matemático. Ideias, São Paulo, n. 10, p. 45-53, 1991.

NOGUEIRA, Z.P. Atividades Lúdicas no Ensino/Aprendizagem de Língua inglesa. Disponível em: < http://www.diaadiaeducacao.pr.gov.br/portals/pde/arquivos/967-4.pdf>Acesso em: 20 jul 2016.

OLIVEIRA, F. S. Lúdico como instrumento facilitador na aprendizagem da educação infantil. Monografia. Universidade Cândido Mendes. Araioses-MA, 2010.

PEDROZA, R. L. S. Aprendizagem e subjetividade: uma construção a partir do brincar. Rev. Dep. Psicol. UFF, Niterói, v. 17, n. 2, 2005. Disponível em: $<$ http://www.scielo.br/scielo.php?script=sci_arttext\&pid=S010480232005000200006\& lng=\&nrm=iso> Acesso em: 20 nov. 2016.

PELEIAS, I. R.(organizador) Didática do ensino da Contabilidade. São Paulo: Saraiva, 2006.

PESSOA, M. A. O lúdico enquanto ferramenta no processo ensinoaprendizagem. Monografia. Instituto de educação física e esportes. Universidade Federal do Ceará. Fortaleza, 2012.

POZO, J. I. Teorias Cognitivas da Aprendizagem. 3. ed. Porto Alegre: Artes médicas, 1998.

PRODANOV, C. C.; FREITAS, E. C. Metodologia do trabalho científico: métodos Criar Educação, Criciúma, v. 6, nº1, janeiro/junho 2017.- PPGE - UNESC 


\section{CRIAR EDUCAÇÃO}

Revista do Programa de Pós-Graduação em Educação - UNESC

e técnicas da pesquisa e do trabalho acadêmico. 2. ed. Novo Hamburgo - RGS: Universidade Feevale, 2013.

RODRIGUES, A. A aula e suas estratégias de ensino. UNOPAR Cient. Ciênc. Human, Educ. V. 16, n. 3, p. 157-161, 2015.

ROSÁRIO, M. I. C. lúdico no ensino aprendizagem: matemática fundamental II. Monografia. Universidade Estadual do Sudoeste da Bahia. Vitória da Conquista, 2013.

SANTOS, S. M. P. A Ludicidade como Ciência. Editora Vozes. Petrópolis. Rio de Janeiro, 2001.

SANTOS, E. A. C.; JESUS, B. C. O lúdico no processo ensino-aprendizagem. Dissertação. Universidad Tecnológica Intercontinental. Assunción, 2010.

SILVA, E. L.; MENEZES, E. M. Metodologia da pesquisa e elaboração de dissertação. 3. ed. Florianópolis: Laboratório de Ensino a Distância da UFSC, 2001.

TEODORO, J. D.; BERWIG, C. G.; CUNHA, J. V. A.; COLAUTO, R. D. Estratégias de Ensino-Aprendizagem: Estudo comparativo no ensino superior nas áreas de educação e ciências contábeis. III Encontro de Ensino e Pesquisa em Administração e Contabilidade. João Pessoa. 2011. 